\title{
The Presence of Transforming Growth Factor- $\alpha$ in the Suckling Rat Small Intestine and Pancreas and the Absence in Rat Milk
}

\author{
BOHUSLAV DVOŘȦK' AND OTAKAR KOLDOVSKÝ \\ Department of Pediatrics, Stecle Memorial Children's Research Center, University of Arizona College of \\ Medicine. Tucson. Arizona 85724
}

\begin{abstract}
Immunoreactive rat transforming growth factor- $\alpha$ (TGF- $\alpha$ ) was measured in rat milk, in the mucosa and lumen of the small intestine, and in the pancreas of suckling and adult rats with a homologous RIA. In contrast to epidermal growth factor, where the main source of epidermal growth factor for sucklings is rat milk, the presence of TGF- $\alpha$ was not detectable in rat milk. The concentrations of TGF- $\alpha$ in the small intestine exhibited similar values in suckling and adult rats, whereas epidermal growth factor levels in the small intestine were several times higher in suckling rats than adults. Overnight fasting in suckling rats resulted in minimal changes in the luminal and mucosal TGF- $\alpha$ content. A positive correlation was established in suckling rats between the TGF- $\alpha$ content in the intestinal lumen (but not mucosa) and the TGF- $\alpha$ content in pancreas. Despite many structural and functional similarities between TGF- $\alpha$ and epidermal growth factor, our present data indicate significant differences in the origin and distribution of these two growth factors in the tract of the small intestine of developing rats. (Pediatr Res 35: 348-353, 1994)
\end{abstract}

Abbreviations

TGF- $\alpha$, transforming growth factor- $\alpha$

EGF, epidermal growth factor

irTGF- $\alpha$, immunoreactive rat TGF- $\alpha$

EGF and TGF- $\alpha$ are known to influence various functions of the gastrointestinal tract (1-9). Both TGF- $\alpha$ and EGF bind to the same receptor (10-12), and all known actions of both ligands appear to be mediated by way of binding to this TGF- $\alpha / \mathrm{EGF}$ receptor; no discrete TGF- $\alpha$ receptor has been identified (13). The smallest form of rat TGF- $\alpha$ is 50 amino acids long and has about $33 \%$ structural homology with rat EGF (14). TGF- $\alpha$ was initially postulated to be an embryonic growth factor $(15,16)$, whereas it is now accepted as an integral physiologic regulator of growth in normal tissue $(17,18)$. The presence of TGF- $\alpha$ and its receptors were demonstrated in the gastrointestinal tract of adult human subjects and rats $(3,7,19-23)$; no studies have been reported in the early postnatal period.

Previous studies from our laboratory demonstrated the presence of EGF in the mucosa of the small intestine of suckling and adult rats $(24,25)$. Interestingly, the EGF content in the small

Received July 23, 1993; accepted October 12, 1993.

Correspondence: Otakar Koldovsky, M.D. PhD. Department of Pediatrics, Steele Memorial Children's Research Center, University of Arizona College of Medicine, Tucson, AZ 85724.

1 On leave of absence from Institute of Microbiology, Academy of Sciences of the Czech Republic, Prague, Czech Republic. intestine of suckling rats was considerably higher than in the adults. In adults, fasting did not change the EGF intestinal content, whereas in sucklings fasting led to a profound decrease of EGF content (24). Further experiments have shown that EGF content in the small intestine was dependent on the intake of milk-borne EGF (25). This finding was in agreement with our previous data demonstrating the absorption of ${ }^{125}$ I-labeled EGF by the gastrointestinal tract of suckling rats (26-29) and the presence of EGF in rat milk $(26,30)$.

Because TGF- $\alpha$ was reported to be present in human milk (31, 32 ), although in small amounts, we decided to test the hypothesis that the TGF- $\alpha$ content of the small intestine in suckling rats is influenced-as is EGF-by the intake of milk-borne TGF- $\alpha$. The absence of detectable levels of TGF- $\alpha$ in rat milk and the results of other experiments did not confirm this hypothesis but indicate a very interesting phenomenon, namely, that the two structurally and functionally related growth factors (EGF and $\mathrm{TGF}-\alpha$ ) in the small intestine of suckling rats are regulated by different factors. A preliminary report of these observations has been published (33).

\section{MATERIALS AND METHODS}

Animals. Several litters of suckling Sprague-Dawley rats, both male and female (12-d-old), and adult female rats (70- to 80-dold) bred in our colony were used in this experiment. Rats were fed a standard laboratory diet (Lab Blox, Tech-Lab, Indianapolis, IN), and the number of pups per litter was adjusted to 10 per mother on $\mathrm{d} 2$ after birth. Pups were fasted for one of four time periods of either $2,4,8$, or $18 \mathrm{~h}$. Control groups of pups were taken directly from the mother and killed at the beginning of the fasting experiment. Fasted pups were kept in plastic cages, which were placed with their bottom half on an electric heating pad to help the pups control their normal body temperature (34). Adult rats were divided into two groups: those fed and those fasted for $18 \mathrm{~h}$. All adult fasted animals had access to drinking water. At the beginning of the experiment and after fasting, sex and body weights were recorded, and suckling rats were stimulated by massage of the anogenital area for urination and defecation.

At the proper time the pups were killed and the small intestine and pancreas quickly removed. The small intestine was separated from the duodenum and divided into three equally long segments, referred to as the proximal, middle, and distal segments. Luminal content of each segment was flushed with ice-cold double-distilled water $(1.5 \mathrm{~mL} / \mathrm{segment}$ in sucklings and $20 \mathrm{~mL} /$ segment in adults), and mucosa was scraped into a previously weighed tube. All tissues and flushes were frozen in liquid nitrogen and then reweighed and stored in $-20^{\circ} \mathrm{C}$. Within $4 \mathrm{wk}$, mucosa and pancreas tissues from sucklings were homogenized in $1.5 \mathrm{~mL}$ (mucosa from adult in $10 \mathrm{~mL}$ ) of PBS ( $0.05 \mathrm{M}$ sodium phosphate, pH 7.4, 0.15 M NaCl) with a Polytron (Speed 8, Brinkman, Rexdal, Canada) for $30 \mathrm{~s}$ and then spun at 106000 
$\times g$ at $4^{\circ} \mathrm{C}$ for $32 \mathrm{~min}$. The supernatant was lyophilized and resuspended (see below) for RIA and protein determination (35).

The total volume of material flushed from each segment was thawed and centrifuged as described above, and the supernatant was then lyophilized for RIA and protein determination. Recovery of TGF- $\alpha$ by this extraction procedure was determined to be in excess of $85 \%$ for all tissues by the addition of tracer doses of ${ }^{125}$ I-rat TGF- $\alpha$ before the initial homogenization.

$R I A$. Rat TGF- $\alpha$ used for iodination and reference standards was obtained from Bachem Bioscience (Philadelphia, PA). TGF$\alpha$ was iodinated by the modification of the chloramine-T method (36). Briefly, $5 \mu \mathrm{g}$ of rat TGF- $\alpha$ was diluted in $50 \mu \mathrm{L}$ of $0.5 \mathrm{M}$ PBS ( $\mathrm{pH} \mathrm{7.4)} \mathrm{and} \mathrm{mixed} \mathrm{with} 10 \mu \mathrm{L}$ of chloramine- $\mathrm{T}$ solution ( $1 \mathrm{mg} / \mathrm{mL}$ of water) and $1 \mathrm{mCi} \mathrm{Na}{ }^{125} \mathrm{I}$ (ICN, Irvine, CA). After $45 \mathrm{~s}, 10 \mu \mathrm{L}$ of $0.25 \%$ mercaptoethanol ( $\mathrm{vol} / \mathrm{vol}$ in water) was added, and the mixture was purified on a Sephadex G-25 column (Sigma Chemical Co., St. Louis, MO) to a specific activity of about $140-180 \mu \mathrm{Ci} / \mu \mathrm{g}$ of growth factor (all chemicals from Sigma Chemical Co.).

The irTGF- $\alpha$ in all samples was determined with a homologous RIA. Lyophilized extracts and flushes were resuspended in 0.05 $\mathrm{mL}$ of $0.05 \mathrm{M}$ acetic acid and $0.95 \mathrm{~mL}$ RIA buffer [0.1 M sodium phosphate, pH 7.4, $0.05 \mathrm{M} \mathrm{NaCl}, 0.1 \%$ Triton X-100 (vol/vol), $0.1 \% \mathrm{BSA}$, and $0.01 \% \mathrm{NaN}_{3}$ (wt/vol). Rabbit antirat TGF- $\alpha$ serum was obtained from Peninsula Laboratories (Belmont, CA) in initial dilution of $1: 15000$. We added $100 \mu \mathrm{L}$ of either TGF$\alpha$ standards or samples to $12 \times 75-\mathrm{mm}$ polystyrene tubes containing $100 \mu \mathrm{L}$ of RIA buffer and $100 \mu \mathrm{L}$ of antiserum and vortexed. Tubes were incubated at $4^{\circ} \mathrm{C}$ for $24 \mathrm{~h}$, and then approximately $15000 \mathrm{cpm}^{125}$ I rat TGF- $\alpha$ (in $100 \mu \mathrm{L}$ of RIA buffer) were added to each tube and vortexed; incubation continued at $4^{\circ} \mathrm{C}$ for an additional $24 \mathrm{~h}$. After the second incubation, $50 \mu \mathrm{L}$ of goat antirabbit IgG serum (Antibodies Inc., Davis, CA) and $50 \mu \mathrm{L}$ of $10 \%$ normal rabbit serum (vol/vol in RIA buffer) were added, and mixtures were incubated for $1 \mathrm{~h}$ at room temperature. Polyethylene glycol, $75 \mu \mathrm{L}$ of $10 \%$, wt/vol in water, $\left(M_{r} 8000\right)$ was added, and the tubes were incubated for an additional $15 \mathrm{~min}$ at room temperature. Tubes were centrifuged at $2500 \times g$ for $30 \mathrm{~min}$, and supernatants were carefully aspirated. The pellets were then counted on a LKB 1442 gamma counter. The TGF- $\alpha$ RIA has a sensitivity within the range of 15 to $400 \mathrm{pg} /$ tube, and all determinations were conducted in duplicate/triplicate, with at least two different concentrations of tissue samples. All duplicate/triplicate RIA values agreed within less than $10 \%$. Competition of irTGF $-\alpha$ within tissue extracts at multiple dilutions demonstrated parallelism with standard rat TGF- $\alpha$. The specificity of rabbit antirat TGF- $\alpha$ serum (guaranteed by vendor for rat TGF- $\alpha$ and human TGF- $\alpha$ ) was tested with rat EGF and mouse EGF. No displacement of rat TGF- $\alpha$ with rate EGF or mouse EGF was observed.

Rat milk analysis. Rat milk samples were collected manually from lactating rats (d 12 of lactation) as described previously (30). Milk samples from several mothers were pooled, frozen in aliquots, and used for other treatment or RIA analysis.

Whole rat milk was diluted with RIA buffer ( $1: 4$ by volume) and spun at $40000 \times g$ at $4^{\circ} \mathrm{C}$ for $30 \mathrm{~min}$, and the whey (without fat drops) was carefully aspirated and spun again (as above). Clear rat milk whey was lyophilized and then resuspended in a small amount of RIA buffer. Whey samples were separated on a Sephadex G-50 column by elution with $0.05 \mathrm{M}$ TRIS buffer [pH $7.4,0.1 \%(\mathrm{wt} / \mathrm{vol}) \mathrm{BSA}]$. Collected fractions $(2 \mathrm{~mL})$, as well as nonseparated rat milk whey and whole rat milk, were assayed for presence of irTGF- $\alpha$ by RIA.

Rat milk samples were mixed (1:1 by volume) with flushes from the stomach, duodenum, or small intestine of 12-d-old suckling rats. Control samples of rat milk were mixed with 0.05 $\mathrm{M}$ PBS. The mixtures were kept for $1 \mathrm{~h}$ in water bath $\left(37^{\circ} \mathrm{C}\right)$ and then spun at $40000 \times g$ at $4^{\circ} \mathrm{C}$ for $30 \mathrm{~min}$. Pellets were discarded, and supernatants were then assayed by RIA.

Pooled mucosa samples from the middle segment of the small intestine of 12-d-old pups were homogenized with ice-cold double-distilled water with the Polytron for $30 \mathrm{~s}$, and half of the amount of homogenate was centrifuged at $106000 \times g$ at $4^{\circ} \mathrm{C}$ for $30 \mathrm{~min}$. Supernatants or mucosa homogenates were mixed with rat milk (1:1 by volume) and incubated for $30 \mathrm{~min}$ in water bath $\left(37^{\circ} \mathrm{C}\right)$ in the presence of $0.05 \mathrm{M}$ PBS (pH 7.4) or $0.1 \mathrm{M}$ glycine- $\mathrm{HCl}$ buffer ( $\mathrm{pH}$ 3.2). Control samples were incubated with proper buffer only. All samples were then frozen, lyophilized, and assayed by RIA.

Recovery studies with rat milk were performed by the addition of rat TGF- $\alpha$ standard (in three different concentrations) to whole rat milk sample, by the addition of rat milk (in five different dilutions) to rat TGF- $\alpha$ standard, or by the addition of ${ }^{125}$ I TGF- $\alpha$ to milk before the separation of whey. Recovery results were $95 \%, 95 \%$, and $85 \%$, respectively.

Statistical analysis. A statistical evaluation was performed with analysis of variance followed by Fisher PLSD (statistical program Statview for Macintosh computers; Abacus Concepts, Inc., Berkeley, CA); a $p$ value of $<0.05$ was considered statistically significant.

\section{RESULTS}

Rat parameters. The average body weight of fed, 12-d-old suckling rats was $27.3 \pm 2.2 \mathrm{~g}$ (mean $\pm \mathrm{SEM}, n=50)$. After $4 \mathrm{~h}$ of fasting the average body weight loss was $0.8 \pm 0.1 \mathrm{~g}(n=9)$, and after $18 \mathrm{~h}$ of fasting it was $2.2 \pm 0.6 \mathrm{~g}(n=12)$. No sex differences were observed between body weights in sucklings. The average body weight of fed 70 - to 80 -d-old adult female rats was $250.0 \pm 45.8 \mathrm{~g}(n=12)$, and body weight loss after $18 \mathrm{~h}$ of fasting was $17.3 \pm 2.6 \mathrm{~g}(n=6)$. Pancreas wet weights, as well as the small-intestine mucosa wet weights, were not significantly affected in either suckling or adult rats by fasting.

Rat milk analysis. Rat milk (d 12 of lactation) was analyzed for the presence of irTGF- $\alpha$ by RIA. The sensitivity of the RIA was $0.15 \mathrm{ng}$ of irTGF- $\alpha / 1 \mathrm{~mL}$ of rat milk. The irTGF- $\alpha$ was not detected either in the whole rat milk or in the rat milk whey by RIA. Furthermore, several treatments of rat milk, including separation on a Sephadex G-50 column, "digestion" by stomach or the small-intestine flushes or with small-intestine mucosa, were performed. Despite all these treatments, no traces of irTGF$\alpha$ in rat milk were found. Recovery studies were performed by the addition of three different concentrations of rat TGF- $\alpha$ standards $(40,100$, and $250 \mathrm{pg} / \mathrm{sample})$ to whole rat milk or to rat milk whey or by the addition of rat milk in several dilutions $(75,50,25,10$, and $5 \%$ solution in water) to rat TGF- $\alpha$ standards. The recovery of irTGF- $\alpha$ in both parts of this study exceeded $95 \%$. The extraction recovery study was performed with ${ }^{125}$ I TGF- $\alpha$. Labeled rat TGF- $\alpha$ was added to diluted rat milk before whey separation, and radioactivity was measured after each step. Final recovery of ${ }^{125}$ I TGF- $\alpha$ in rat milk whey was about $85 \%$.

The presence of immunoreactive TGF- $\alpha$ in tissues was expressed either as a concentration or as a total content. The concentration was defined as total amount of irTGF- $\alpha$ per gram organ wet weight or per milligram extractable tissue protein. The total content of irTGF- $\alpha$ was defined as total amount of TGF- $\alpha$ per organ or per gram body weight. The irTGF- $\alpha$ level in the small-intestine lumen was expressed as a total content only because the concentration values exhibited large variability (especially from fasted animals, where concentrations of extractable protein in the lumen flushes were significantly reduced), and there is a possibility of introduction of arithmetic artifacts.

$T G F-\alpha$ in small intestine and pancreas. Results from the smallintestine mucosa of fed (control) suckling and adult rats are summarized in Table 1. The concentrations of irTGF- $\alpha$ in the small intestine of suckling and adult rats were not significantly different, but the distribution of irTGF- $\alpha$ in three segments has shown a different pattern. In contrast to the adults, where values were similar along the three lengths of the small intestine, sucklings exhibited a significant increase from the proximal to distal 
Table 1. TGF- $\alpha$ in small-intestine mucosa and pancreas*

\begin{tabular}{|c|c|c|c|c|c|c|}
\hline & \multicolumn{3}{|c|}{ Sucklings } & \multicolumn{3}{|c|}{ Adults } \\
\hline & $n$ & $\mathrm{ng} / \mathrm{g}$ Wet weight & $\mathrm{pg} / \mathrm{mg}$ Protein & $n$ & $\mathrm{ng} / \mathrm{g}$ Wet weight & $\mathrm{pg} / \mathrm{mg}$ Protein \\
\hline \multicolumn{7}{|c|}{ Small intestine segments $\dagger$} \\
\hline Proximal & 6 & $4.1 \pm 0.6^{a} \ddagger$ & $114.0 \pm 15.0^{a}$ & 6 & $6.4 \pm 0.6^{a}$ & $134.3 \pm 9.5^{a}$ \\
\hline Middle & 7 & $9.4 \pm 1.0^{a t} \ddagger$ & $225.0 \pm 21.5^{b} \ddagger$ & 6 & $6.2 \pm 0.6^{a}$ & $133.7 \pm 4.7^{a}$ \\
\hline Distal & 8 & $11.6 \pm 2.4^{b}$ & $233.8 \pm 45.5^{h^{\top}}$ & 6 & $6.6 \pm 1.0^{a}$ & $101.7 \pm 5.2^{a}$ \\
\hline Pancreas & 9 & $29.8 \pm 9.5 \ddagger$ & $699.2 \pm 236.3$ & 6 & $162.2 \pm 82.0$ & $1963.8 \pm 1166.0$ \\
\hline
\end{tabular}

* Values are means \pm SEM.

+ Values from the small intestinal segments with different superscript letters are significantly different from others in the same column $(p<0.05)$.

$\ddagger$ Statistically significant difference between corresponding data from suckling and adult rats $(p<0.05)$.

part. In the pancreatic tissues of both sucklings and adults, the concentrations of irTGF- $\alpha$ were extremely varied. Despite this, adult rats exhibited significantly higher concentrations (ranging from $16.5-354.0 \mathrm{ng} / \mathrm{g}$ wet weight or $182.6-5216.5 \mathrm{pg} / \mathrm{mg}$ protein) in comparison with sucklings (ranging from $6.2-74.8 \mathrm{ng} / \mathrm{g}$ wet weight or $127.8-1851.1 \mathrm{pg} / \mathrm{mg}$ protein). Comparison of the total content of irTGF- $\alpha$ in the mucosa of suckling and adult rats, expressed as per gram body weight (Table 2), showed no significant differences between the two age groups; interestingly, the luminal content expressed per gram body weight was about 7 -fold higher in adults than in the sucklings.

The effect of 18-h fasting on the total content of irTGF- $\alpha$ in the small-intestine mucosa and lumen of sucklings and adults is shown in Table 2. In adult rats, fasting led to a significant decrease in luminal irTGF- $\alpha$ content, whereas in sucklings no remarkable effect of 18-h fasting was observed. Moreover, significant differences were observed between mucosal and luminal irTGF- $\alpha$ contents in the suckling and adult rats. In sucklings (fed or fasted), only about $9.4 \%$ ( $10.5 \%$ and $8.3 \%$, respectively) of the total content of irTGF- $\alpha$ in the small intestine was present in the lumen, whereas in adult rats the luminal content represented about $50.9 \%$ ( $58.1 \%$ for fed and $43.6 \%$ for fasted) of the total intestinal irTGF- $\alpha$ content. Fasting for $18 \mathrm{~h}$ had no significant effect on the total content or the concentration in the pancreas of either suckling or adult rats, but a large variation in irTGF- $\alpha$ levels was observed.

Suckling rats were fasted for several different time periods (between 2-18 h) to better understand the fate of TGF- $\alpha$ in the small intestine. The total contents of irTGF- $\alpha$ in the mucosa and lumen in the segments of the small intestine of suckling rats are shown in Figure 1. Although the mucosal irTGF- $\alpha$ level in the proximal segment was not significantly changed during fasting, the middle and distal segments exhibited statistically significant decreases of irTGF- $\alpha$ content during fasting (after 8 and $18 \mathrm{~h}$ ) in comparison with the fed (control) pups. The amounts in luminal flushes from all three segments exhibited similar levels and were not significantly affected by fasting.

The pancreas of suckling rats exhibited great variability in
irTGF- $\alpha$ levels within all fed or fasted groups (Fig. 2), and no statistically significant differences between fed and fasted groups of animals were found. When individual data from the pancreas of all suckling rats studied were compared with the data from the lumen of the small intestine for each animal, a significant correlation was observed. Both linear and polynomial regression analysis demonstrated a significant relationship between luminal and pancreatic irTGF- $\alpha$ levels. In contrast, the irTGF- $\alpha$ values in the small-intestine mucosa did not show any dependence on irTGF- $\alpha$ levels (Fig. 3). Correlation coefficients $(r)$ from calculations of linear regression for the proximal, middle, distal, and total lumen levels were $0.685,0.538,0.650$, and 0.643 , respectively. In adult rats no correlation was found.

\section{DISCUSSION}

TGF- $\alpha$ is a member of the EGF family. The structural similarity (about $33 \%$ ) between TGF- $\alpha$ that is 50 amino acids long and the EGF that is 53 residues long (including all six cysteines), as well as functional resemblance, have suggested that these two factors share a similar origin and fate in the developing small intestine. The epithelium of the small intestine is one of the most dynamic epithelial surfaces in the body, with high proliferation and differentiation rates (37). The factors that coordinate these fast and well-organized processes are not well defined, but EGF has long been regarded as a likely modulator of gastrointestinal epithelial growth and differentiation $(1,3,38-43)$, and similar physiologic functions are suggested for TGF- $\alpha(7-9,23,44,45)$.

Whereas previous reports from our laboratory dealt with the origin, "survival," and fate of milk-borne EGF in the gastrointestinal tract of suckling rats, the present study has focused on the presence of TGF- $\alpha$ in rat milk and its distribution in the small intestine of suckling rats. This study performed in both adult and 12-d-old suckling rats not only extends the recently published report regarding the content of irTGF- $\alpha$ in various organs during rat development (46) and the localization of TGF$\alpha$ immunoreactivity in the jejunal epithelial compartments of adult rats (45) but also reveals the significant differences between

Table 2. TGF- $\alpha$ in small intestine and pancreas: effect of fasting*

\begin{tabular}{|c|c|c|c|c|}
\hline & \multicolumn{2}{|c|}{ Sucklings } & \multicolumn{2}{|c|}{ Adults } \\
\hline & Fed & Fasted & Fed & Fasted \\
\hline \multicolumn{5}{|l|}{ Nanograms per organ } \\
\hline Small-intestine mucosa & $4.4 \pm 1.1^{a} \dagger$ & $3.2 \pm 0.3^{a} \dagger$ & $28.1 \pm 3.4^{a}$ & $21.0 \pm 2.0^{a}$ \\
\hline Small-intestine lumen & $0.5 \pm 0.0^{a} \dagger$ & $0.5 \pm 0.1^{a} \dagger$ & $34.8 \pm 2.1^{a}$ & $16.5 \pm 1.5^{b}$ \\
\hline Lumen as $\%$ of total small-intestine content & $10.5 \pm 0.7^{a} \dagger$ & $8.3 \pm 1.7^{u} \dagger$ & $58.1 \pm 1.8^{a}$ & $43.6 \pm 1.6^{h}$ \\
\hline Pancreas & $5.0 \pm 1.7^{a} \dagger$ & $11.4 \pm 4.4^{u} \dagger$ & $131.8 \pm 91.3^{a}$ & $139.6 \pm 64.7^{a}$ \\
\hline \multicolumn{5}{|l|}{ Picograms per gram of body weight } \\
\hline Small-intestine mucosa & $155.2 \pm 44.6^{a}$ & $112.9 \pm 10.8^{a} \dagger$ & $95.7 \pm 7.0^{a}$ & $87.3 \pm 4.6^{a}$ \\
\hline Small-intestine lumen & $17.2 \pm 0.7^{\circ} \uparrow$ & $21.1 \pm 6.9^{a} \dagger$ & $141.0 \pm 5.9^{a}$ & $67.2 \pm 3.4^{h}$ \\
\hline Pancreas & $173.1 \pm 59.6^{a}$ & $499.7 \pm 210.5^{a}$ & $258.0 \pm 137.0^{a}$ & $503.0 \pm 234.0^{a}$ \\
\hline
\end{tabular}

* Values are mean \pm SEM. $n=5-8$ animals/group. Values from suckling or adult rats with the different superscript letters are significantly different from others in the same row $(p<0.05)$.

+ Statistically significant difference between corresponding data from suckling and adult rats $(p<0.05)$. 

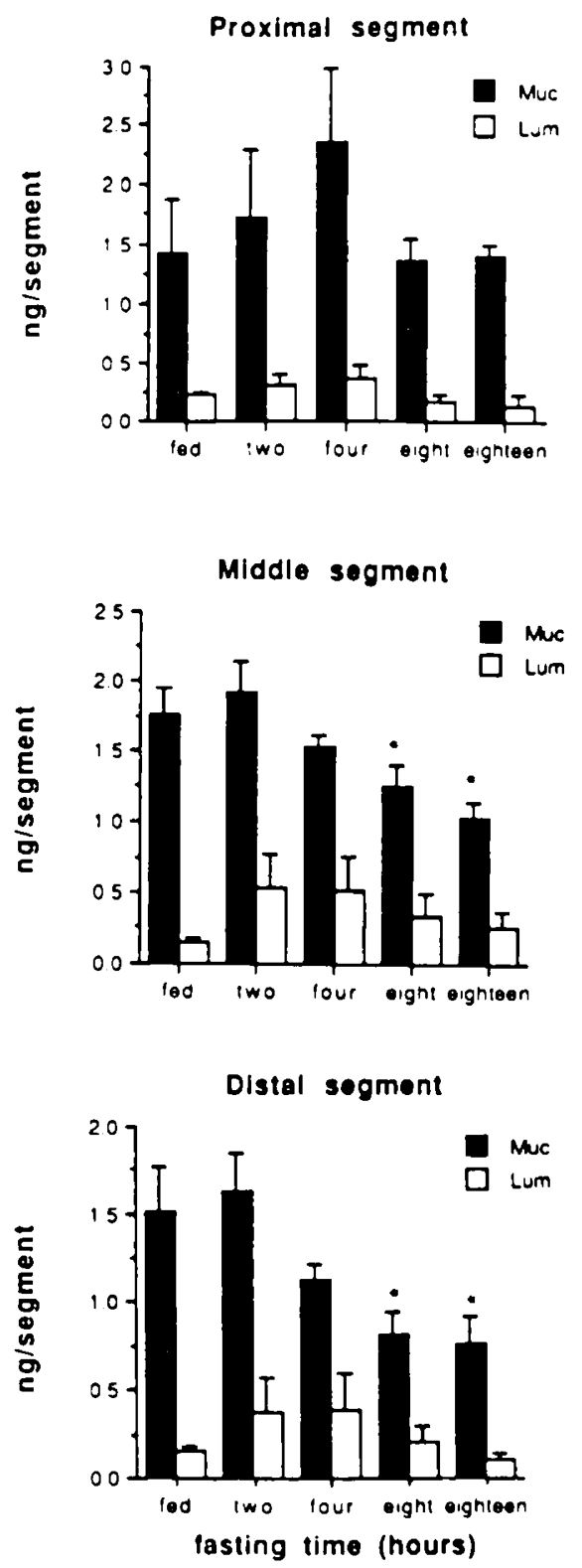

Fig. 1. TGF- $\alpha$ content in the small-intestine segments of suckling rats during fasting. Top panel, Proximal segment; middle panel, middle segment; bottom panel, distal segment. Columns are mean values; vertical lines are SEM; $n=6$ to 9 sucklings (originated from five different litters). Solid columns are values of small-intestine mucosa, open columns are luminal values. *, Statistically significant differences between mean values of fed (control) and corresponding fasted animals $(p<0.05)$.

the distribution and the origin of TGF- $\alpha$ and EGF in the small intestine of suckling rats.

Large amounts of biologically active peptides, including hormones and growth factors, are present in milk from various species (47-49), and their active role in the developing gastrointestinal tract has been postulated frequently $(20,41,50,51)$. Although high levels of EGF have been detected in milk from many mammalian species, only two reports are available regarding the presence of TGF- $\alpha$ in human milk $(31,32)$, with no reports found on TGF- $\alpha$ content in rat milk. To prove the presence or lack of TGF- $\alpha$ in rat milk, whole rat milk in several different dilutions, as well as rat milk whey, were assayed by RIA. TGF- $\alpha$ was undetectable in whole rat milk and in rat milk whey. A previous study from our laboratory confirmed the existence of three distinct immunoreactive forms of EGF in rat milk, which can be revealed after enzymatic digestion or purifi-

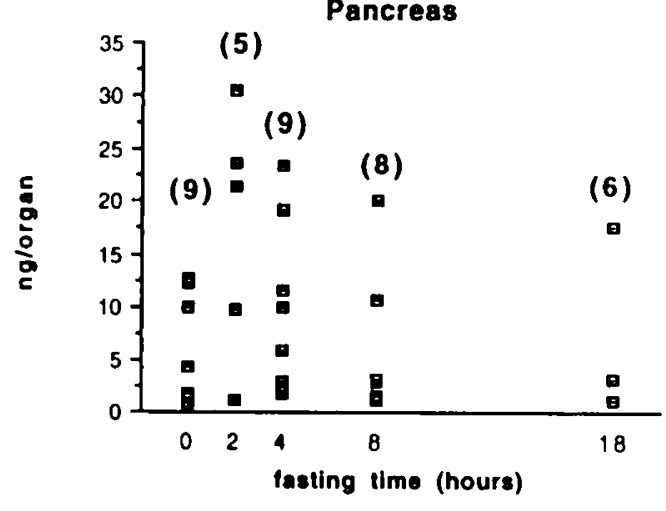

Fig. 2. TGF- $\alpha$ content in the pancreas of suckling rats during fasting. Mean values \pm SEM [including $n$ (numbers in parentheses) are given because in several cases symbols used overlap] for individual fasting periods are as follows: fed, $5.0 \pm 1.7$ (nine rats); $2 \mathrm{~h}, 17.3 \pm 5.2$ (five rats); $4 \mathrm{~h}, 8.8 \pm 2.7$ (nine rats); $8 \mathrm{~h}, 5.3 \pm 2.4$ (eight rats); and $18 \mathrm{~h}, 11.4$ \pm 4.4 (six rats)

The small intestinal lumen

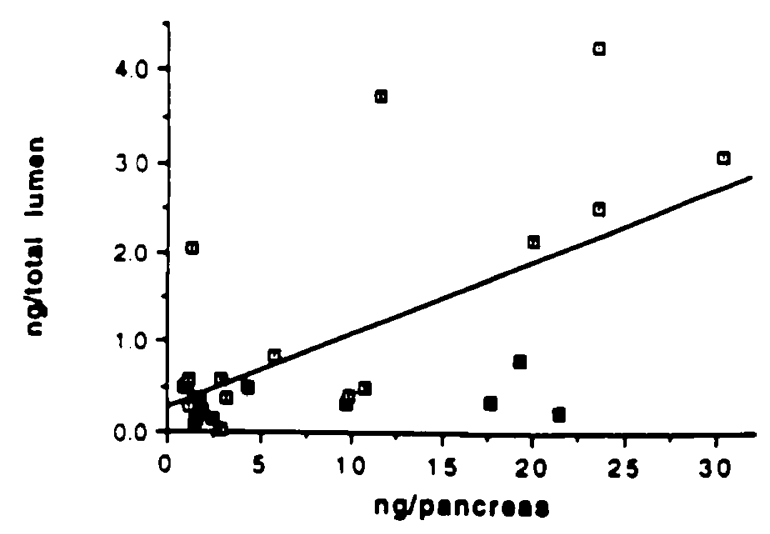

The small intestinal mucose

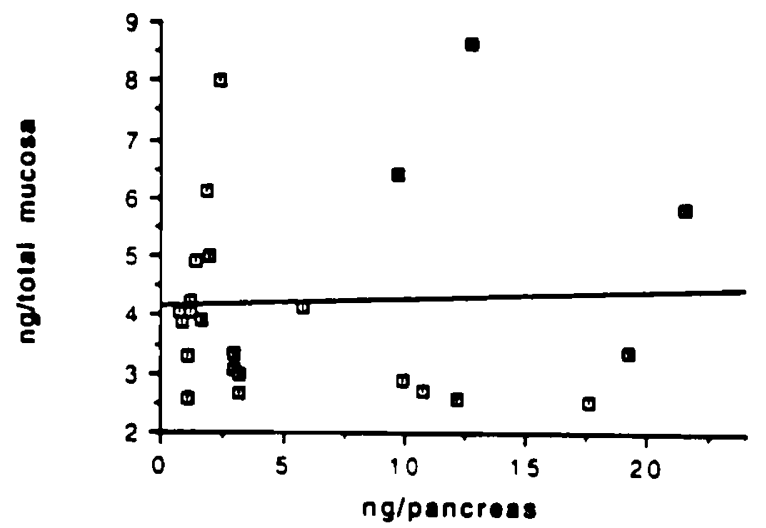

Fig. 3. Comparison of individual TGF- $\alpha$ data from the pancreas and the entire small-intestine mucosa and lumen of suckling rats. Top panel, Linear regression of individual pancreatic and small-intestine luminal values. Formula for linear regression is $\mathrm{y}=0.25181 \pm 8.177 \mathrm{e}^{-2} \mathrm{x}, R^{2}=$ 0.391 ; for polynomial regression it is $y=0.13698-4.3255 \mathrm{e}^{-5} \mathrm{x}+$ $7.8089 \mathrm{e}^{-4} \mathrm{x}^{2}, R^{2}=0.469$. Bottom panel, Linear regression of individual pancreatic and small-intestine mucosal values. $n=24$ to 27 suckling rats (originated from five different litters).

cation of rat milk (30). Therefore, several other treatments were performed with rat milk, including gel filtration or incubation with gastrointestinal flushes or tissues. None of these treatments revealed the presence of TGF- $\alpha$ in rat milk detectable by ho- 
mologous RIA.

On the other hand, TGF- $\alpha$ was detected in all segments of the small intestine of both suckling and adult rats. The concentrations of TGF- $\alpha$ in the tissue of the small intestine were similar between suckling and adult rats. These data are in contrast with EGF data where suckling rats had several times higher levels of EGF in the small intestine compared with adults $(24,25)$. The distribution of TGF- $\alpha$ along the small intestine in suckling rats is also different from adult rats. In adult rats, TGF- $\alpha$ values in all three segments of the intestine are similar, whereas suckling rats showed a clear increase of TGF- $\alpha$ concentration from the proximal to distal part. The TGF- $\alpha$ content in the lumen of the small intestine or in each segment of the intestine separately represents only about $8-11 \%$ of the total content of TGF- $\alpha$ in the small intestine of sucklings. Moreover, TGF- $\alpha$ levels in the lumen, as well as the ratio between mucosal and luminal levels, are not significantly changed during fasting of suckling rats. These results indicate a considerable difference between TGF- $\alpha$ and EGF in the developing small intestine. Schaudies $e t$ al. (24) and Grimes et al. (25) have demonstrated that the content of EGF in the gastrointestinal tract is significantly elevated during the suckling period and that these levels of EGF are dependent on milk-borne EGF intake. Luminal EGF levels in sucklings reached $40-70 \%$ of the total content of EGF in the entire small intestine. In contrast to EGF, a significantly higher content of TGF- $\alpha$ was observed in the intestine tissue than in the lumen. This higher content remained at a relatively stable level during fasting, supporting our conclusion about differences in the origin and processing of TGF- $\alpha$ in the developing tract of the small intestine in comparison with EGF. Fasting of suckling rats for 8 or $18 \mathrm{~h}$ resulted in considerable decrease the total EGF content in the small-intestine tissue or lumen, whereas the total TGF- $\alpha$ levels were not significantly changed during the same period of fasting. Fasting for more than $18 \mathrm{~h}$ was not performed to keep experimental conditions similar to other EGF studies $(24,25)$ and to avoid possible introduction of nonphysiologic conditions. Furthermore, the fact that adults (in comparison with sucklings) exhibited a higher total content of TGF- $\alpha$ in the small-intestine mucosa and lumen and a significant decrease of luminal levels during fasting may be the result of higher endogenous production of TGF- $\alpha$ in adults or by faster absorption of TGF- $\alpha$ in sucklings.

The finding of high concentrations of TGF $-\alpha$ in the pancreatic tissues of suckling rats raises the question of whether the pancreas is a source of TGF- $\alpha$ in the small intestine. Fasting for several time periods had no statistically significant effect on the level of TGF- $\alpha$ in the pancreas. At the same time, the levels of TGF- $\alpha$ in the pancreas varied from animal to animal, not only between different experimental groups but also within the same fed or fasted group from the same litter. The high variation of TGF- $\alpha$ can be caused by pulsative excretion of TGF- $\alpha$ from the pancreas. Despite the fact that the TGF- $\alpha$ concentration in the intestine varied much less than that in the pancreas, all individual data on the pancreas and intestine from each rat (fed or fasted) were compared. This comparison revealed a statistically significant correlation between TGF- $\alpha$ levels in the small-intestine lumen and the pancreas of suckling rats. Both linear and polynomial regression confirmed the quantitative dependence of TGF- $\alpha$ levels in the lumen in the pancreas. On the other hand, no correlation has been found among other TGF- $\alpha$ data; in adult rats no correlation has been observed at all. These data support the hypothesis that TGF- $\alpha$ in the pancreas may influence the levels of TGF- $\alpha$ in the small intestine of developing rats.

The present report is the first direct quantification of TGF- $\alpha$ levels in the entire small intestine and pancreas of sucklings and adults and simultaneously the first article reporting the absence of detectable levels of irTGF- $\alpha$ in rat milk. Despite many structural and functional similarities between TGF- $\alpha$ and EGF, these results indicate significant differences in the origin and levels of these two growth factors in the tract of the small intestine of developing rats.

\section{REFERENCES}

1. Johnson LR, Guthrie PD 1980 Stimulation of rat oxyntic gland mucosal growth by epidermal growth factor. Am J Physiol 238:G45-G49

2. Konturek SJ, Radecki T, Brzozowski T, Piastucki I, Dembinski A, DembinskaKiec A, Zmuda A, Gryglewski R, Gregory H 1981 Gastric cytoprotection by epidermal growth factor. Gastroenterology 81:438-443

3. Al-Nafussi AI, Wright NA 1982 The effect of epidermal growth factor (EGF) on cell proliferation in the gastrointestinal mucosa in rodents. Virchows Arch Cell Pathol 40:63-69

4. Skinner KA, Soper BD, Tepperman BL 1984 Effect of sialoadenectomy and salivary gland extracts on gastrointestinal mucosal growth and gastrin levels in the rat. J Physiol (Lond) 351:1-12

5. Rhodes JA, Tam JP, Finke U, Saunders M, Bernanke J, Silen W, Murphy RA 1986 Transforming growth factor $\alpha$ inhibits secretion of gastric acid. Proc Natl Acad Sci USA 83:3844-3846

6. Konturek SJ, Dembinski A, Warzecha Z. Brzozowski T, Gregory H 1988 Role of epidermal growth factor in healing of chronic gastroduodenal ulcers in rats. Gastroenterology 94:1300-1307

7. Beauchamp RD, Barnard JA, McCutchen CM, Chemer JA, Coffey RJ 1989 Localization of transforming growth factor- $\alpha$ and its receptor in gastric mucosa cells. J Clin Invest 84:1017-1023

8. Koyama S, Podolsky DK 1989 Differential expression of transforming growth factors $\alpha$ and $\beta$ in rat intestinal epithelial cells. J Clin Invest 83:1768-1773

9. Konturek SJ, Brzozowski T, Majka J, Dembinski A, Slomiany A, Slomiany BL 1992 Transforming growth factor alpha and epidermal growth factor in protection and healing of gastric mucosal injury. Scand J Gastroenterol 27:649-655

10. Todaro GJ, Fryling C, De Larco JE 1980 Transforming growth factors produced by certain human tumor cells: polypeptides that interact with epidermal growth factor receptors. Proc Natl Acad Sci USA 77:5258-5262

11. Carpenter G, Stoscheck CM, Preston YA, De Larco JE 1983 Antibodies to the epidermal growth factor receptor block the biological activities of sarcoma growth factor. Proc Natl Acad Sci USA 80:5627-5630

12. Massaque J 1983 Epidermal growth factor-like transforming growth factor. J Biol Chem 258:13614-13620

13. Derynck R 1988 Transforming growth factors- $\alpha$. Cell 54:593-595

14. Marquardt H, Hunkapiller MW, Hood LE, Todaro GJ 1984 Rat transforming growth factor type 1: structure and relation to epidermal growth factor. Science 223:1079-1082

15. Lee DC, Rochford R, Todaro GJ, Villarreal LP 1985 Developmental expression of rat transforming factor- $\alpha$ mRNA. Mol Cell Biol 5:3644-3646

16. Twardzik DR 1985 Differential expression of transforming growth factor- $\alpha$ during prenatal development of the mouse. Cancer Res 45:5413-5416

17. Skinner MK, Coffey RJ 1988 Regulation of ovarian cell growth through the local production of transforming growth factor- $\alpha$ by theca cells. Endocrinology 123:2632-2638

18. Skinner MK, Takacs K, Coffey RJ 1989 Transforming growth factor- $\alpha$ gene expression and action in the seminiferous tubule: peritubular cell-sertoli cell interactions. Endocrinology 124:845-854

19. Miettinen PJ, Perheentupa J, Otonkoski T, Lahteenmaki A, Panula P 1989 EGF- and TGF $\alpha$-like peptides in human fetal gut. Pediatr Res 26:25-30

20. Malden LT, Novak U, Burgess AW 1989 Expression of transforming growth factor alpha messenger RNA in the normal and neoplastic gastrointestinal tract. Int J Cancer 43:380-384

21. Goodlad RA, Lee CY, Wright NA 1990 TGF- $\alpha$ and intestinal epithelial cell proliferation in parenterally fed rats. Gut 31:A1197 (abstr)

22. Bielanski WJ, Keogh JP, Wang SL, Liu J, Konturek SJ, Slomiany A, Slomiany BL 1991 Transforming growth factor- $\alpha$ binds to the epidermal growth factor receptor in gastric mucosa. Biochem Int 25:419-427

23. Miettinen PJ 1993 Transforming growth factor $\alpha$ and epidermal growth factor expression in human fetal gastrointestinal tract. Pediatr Res 33:481-486

24. Schaudies RP, Grimes J, Davis D, Rao RK, Koldovskỳ O 1989 EGF content in the gastrointestinal tract of rats: effect of age and fasting/feeding. Am J Physiol 256:G856-G861

25. Grimes J, Schaudies RP, Davis D. Williams C, Curry BJ, Walker MD, Koldovsky O 1992 Effect of short-term fasting/refeeding on epidermal growth factor content in the gastrointestinal tract of suckling rats. Proc Soc Exp Biol Med 199:75-80

26. Thornburg W, Matrisian L, Magun B, Koldovsky O 1984 Gastrointestinal absorbtion of epidermal growth factor in suckling rats. Am J Physiol 246:G80-G85

27. Thornburg W, Rao RK, Matrisian LM, Magun BE, Koldovsky O 1987 Effect of maturation on gastrointestinal absorption of epidermal growth factor in rats. Am J Physiol 253:G68-G71

28. Rao RK, Koldovsky O, Grimes J, Williams C. Davis TP 1991 Regional differences in gastrointestinal processing and absorption of epidermal growth factor in suckling rats. Am J Physiol 261:G790-G798

29. Kong W, Koldovsky O, Rao RK 1992 Appearance of exogenous epidermal growth factor in liver, bile, and intestinal lumen of suckling rats. Gastroenterology 102:661-667

30. Schaudies RP, Grimes J, Wray HL, Koldovsky O 1990 Identification and partial characterization of multiple forms of biologically active EGF in rat milk. Am J Physiol 259:G1056-G1061

31. Connolly JM, Rose DP 1988 Epidermal growth factor-like proteins in breast fluid and human milk. Life Sci 42:1751-1756

32. Okada M, Ohmura E, Kamiya Y, Murakami H, Onoda N, Iwashita M, Wakai 
K, Tsushima T, Shizume K 1991 Transforming growth factor (TGF- $\alpha$ ) in human milk. Life Sci 48:1151-1156

33. Dvorák B, Koldovsky O 1993 Transforming growth factor $\alpha$ (TGF- $\alpha$ ) in the jejunoileum of suckling rats: effect of fasting. Gastroenterology 104:A619 (abstr)

34. Hahn P, Koldovsky O 1967 Utilization of Nutrients During Postnatal Development. Pergamon Press, Oxford, UK

35. Lowry OH, Rosebrough NJ, Farr AL, Randall RJ 1951 Protein measurement with the Folin phenol reagent. J Biol Chem 193:265-275

36. Greenwood FC, Hunter WM, Glover JS 1963 The preparation of ${ }^{131}$ I-labeled human growth hormone of high specific radioactivity. Biochem J 89:114123

37. Cheng H, Leblond C 1974 Origin, differentiation and renewal of the four main epithelial cell types in the mouse small intestine. Am J Anat 141:461-480

38. Malo C, Menard D 1982 Influence of epidermal growth factor on the development of suckling mouse intestinal mucosa. Gastroenterology 83:28-35

39. Oka Y, Ghishan FK, Greene LH, Orth DN 1983 Effect of mouse epidermal growth factor-urogastrone on the functional maturation of rat intestine. Endocrinology 112:940-944

40. Dembinski AB, Johnson LR 1985 Effect of epidermal growth factor on the development of rat gastric mucosa. Endocrinology 1!6:90-94

41. Berseth CL 1987 Enhancement of intestinal growth in neonatal rats by epidermal growth factor in milk. Am J Physiol 253:G622-G665

42. Britton JR, George-Nascimemto C, Koldovsky O 1988 Luminal hydrolysis of recombinant human epidermal growth factor in the rat gastrointestinal tract: segmental and developmental differences. Life Sci 43:1339-1347

43. Goodlad RA, Lee CY, Wright NA 1992 Cell proliferation in the small intestine and colon of intravenously fed rats: effects of urogastrone-epidermal growth factor. Cell Prolif 25:393-404

44. Cartlidge SA, Elder JB 1989 Transforming growth factor $\alpha$ and epidermal growth factor levels in normal human gastrointestinal mucosi. Br J Cancer 60:657-660

45. Barnard JA, Polk WH, Moses HL, Coffey RJ 1991 Production of transforming growth factor- $\alpha$ by normal rat small intestine. Am J Physiol 261:C994C 1000

46. Brown PI, Lam R, Lakshmanan J, Fisher DA 1990 Transforming growth factor alpha in developing rats. Am J Physiol 259:E256-E260

47. Koldovsky O 1980 Hormones in milk. Life Sci 26:1833-1836

48. Koldovsky O, Thornburg W 1987 Hormones in milk. J Pediatr Gastroenterol Nutr 6:172-196

49. Koldovsky O 1989 Critical review: search for role of milk-borne biologically active peptides for the suckling. J Nutr 119:1543-1551

50. O'Loughlin EV, Chung M, Hollenberg M, Hayden J, Zahavi I, Gall DG 1985 Effect of epidermal growth factor on ontogeny of the gastrointestinal tract. Am J Physiol 249:G674-G678

51. Pollack PF, Goda T, Colony PC. Edmond J, Thornburg W. Korc M, Koldovsky O 1987 Effects of enterally fed epidermal growth factor on the small and large intestine of the suckling rat. Regul Pept 17:121-132 